$$
\begin{gathered}
\text { Co0-382-105 } \\
\text { N71-14967 } \\
\text { NASA CR-115884 }
\end{gathered}
$$

\title{
ABSOLUTE SCALE FOR RADIATION AGES \\ OF STONY METEORITES
}

\author{
G.F. Herzog and Edward Anders
}

Enrico Fermi Institute and Department of Chemistry

University of Chicago, Chicago, Illinois 60637

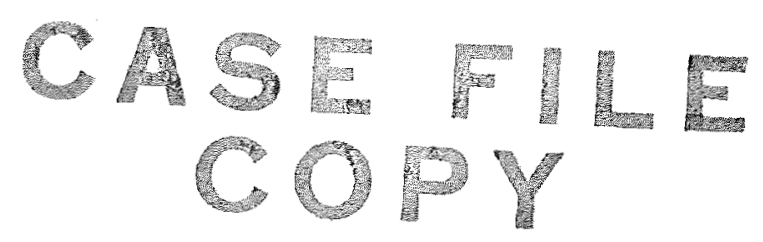




\section{ABSOLUTE SCALE FOR RADIATION AGES}

OF STONY METEORITES

\section{G.F. Herzog and Edward Anders}

Enrico Fermi Institute and Department of Chemistry University of Chicago, Chicago, I11inois 60637

Abstract. Absolute production rates of $\mathrm{He}^{3}$ and $\mathrm{Ne}^{21}$

in L-chondrites have been determined from a least-squares fit of noble-gas to $\mathrm{Al}^{26}$ data, for meteorites of radiation age $<2$ Myr. in which $\mathrm{Al}^{26}$ has not been built up to saturation levels. The values obtained, $2.48 \pm 0.23$ and $0.466 \pm 0.031 \mathrm{ccSTP}^{-1} \mathrm{Myr}^{-1}$, are $24 \%$ higher than conventional values, based on $\mathrm{H}^{3}$ measurements. Apparently all published radiation ages of stony meteorites based on conventional production rates are too high by $24 \%$.

\section{INTRODUCTION}

Radiation ages of meteorites are based on measurement of a radioactive and a stable cosmogenic nuclide. The radioactive nuclide measures the effective cosmic-ray flux in the meteorite, while the stable nuclide integrates this flux over time. If $S$ is the concentration of the stable nuclide, in atoms $/ g$, and $A_{O}^{l^{\prime}}$ is the saturation activity of the radioactive nuclide, in disintegrations $\sec ^{-1} \mathrm{~g}^{-1}$, then the radiation age $\underline{t}$ equals:

$$
t=\left(S / A_{0}^{r}\right)\left(P_{r} / P_{S}\right)
$$

where $\mathrm{P}_{r}$ and $\mathrm{P}_{\mathrm{S}}$ are the production rates of the radioactive and stable species, in atoms sec ${ }^{-1} \mathrm{~g}^{-1}$ (Anders, 1963). 
Unfortunately, $\mathrm{P}_{Y}$ and $\mathrm{P}_{\mathrm{S}}$ are hard to evaluate. They involve the cosmic ray flux as a function of time and energy and the production cross sections as a function of energy for all nuclear reactions leading to the two nuclides in question. Much of this information is not known.

In order to circumvent this difficulty, one usually chooses pairs of nuclides that are isobaric or at least fairly close in mass number: $\mathrm{He}^{3}-\mathrm{H}^{3}, \mathrm{Ne}^{22}-\mathrm{Na}^{22}, \mathrm{Ne}^{21}-\mathrm{Al}^{26}, \mathrm{Ar}^{36}-\mathrm{Cl}^{36}$, $\mathrm{Ar}^{38}-\mathrm{Ar}^{39}$, and $\mathrm{Kr}^{78}-\mathrm{Kr}^{81}$. One can then assume, with some justification, that the cross sections of both nuclides have the same energy dependence for all relevant target nuclides. $\mathrm{P}_{\mathrm{r}} / \mathrm{P}_{\mathrm{S}}$ then simplifies to the ratio of two averaged cross sections, which may be determined in the laboratory for a suitable target element and bombarding energy.

In practice, even further simplifications are made. Measurements of radioactive nuclides are often unavailable, and it has therefore become customary to assume constant cosmicray fluxes for all meteorites, and to calculate radiation ages from stable nuclides alone, using fixed production rates. For chondrites at least, this is not a bad assumption, because their $\mathrm{H}^{3}$ and $\mathrm{Al}^{26}$ contents are constant to $\pm 15 \%$ in the majority of cases (Begemann et al., 1959; Geiss et al., 1960: Goebel and Schmidlin, 1960; Bainbridge et al., 1962; Begemann, 1966 ; Heymann and Anders, 1967; Fuse and Anders, 1969).

The ages derived by different methods are reasonably consistent with each other, and thus there is no reason to suspect a gross error in the above assumptions. Nonetheless, 
it is perhaps a 1 ittle disconcerting to realize that the radiation age scale for stony meteorites rests almost entirely on eight $H^{3}$ measurements in chondrites (see Kirsten et al., 1963, for references) and an $\mathrm{H}^{3} / \mathrm{He}^{3}$ production ratio of 0.5 observed in the proton bombardment of iron (Schaeffer and Zähringer, 1958). From these data, an average $\mathrm{He}^{3}$ production rate of $2.00 \times 10^{-8}$ ccSTP $\mathrm{g}^{-1} \mathrm{Myr}^{-1}$ has been derived for ordinary chondrites (Kirsten et al., 1963). Nearly all other dating methods for stones are directly or indirectly tied to this rate. For example, the $\mathrm{Ne}^{21}$ production rate in L-chondrites $\left(0.377 \operatorname{ccSTP~}^{-1} \mathrm{Myr}^{-1}\right.$; Heymann et $\underline{\text { al }}$, 1968; Cobb, 1965, quoted by Heymann, 1967) has been derived from the above value by way of the observed average $\mathrm{He}^{3} / \mathrm{Ne}^{21}$ ratio of 5.3 (Heymann, 1967).

Kruger and Heymann (1968) have pointed out, however, that the $\mathrm{H}^{3} / \mathrm{He}^{3}$ production ratio depends on the neutron-to-proton ratio of the target element. Using measured values for $\mathrm{Mg}, \mathrm{Si}$, and $\mathrm{Fe}$, and an interpolated value for $\mathrm{O}$, they estimate a $\mathrm{H}^{3} / \mathrm{He}^{3}$ production ratio of 0.63 for hypersthene chondrites. This corresponds to a $\mathrm{He}^{3}$ production rate of $2.6 \times 10^{-8} \operatorname{ccSTP~}^{-1} \mathrm{Myr}^{-1}$, $30 \%$ higher than the conventional value.

\section{CALCULATION OF ABSOLUTE PRODUCTION RATES}

In view of these uncertainties, we have attempted to estimate absolute $\mathrm{He}^{3}$ and $\mathrm{Ne}^{21}$ production rates without recourse to nuclear cross sections. Instead, we have used a cosmogenic radionuclide, $\mathrm{Al}^{26}$, as an indicator of absolute age. The $\mathrm{Al}^{26}$ activity of a meteorite, A, is related to the saturation value 
after an infinitely long bombardment, $A_{O}$, by the equation of radioactive growth:

$$
A=A_{0}\left(1=e^{-\lambda t}\right)
$$

Here $\lambda$ is the decay constant of $\mathrm{Al}^{26}\left(0.94 \mathrm{Myr}^{-1}\right)$ and $t$ is the radiation age. When $A$ is appreciably less than $A_{0}$, this equation can be used to determine $\underline{t}$, provided that $A_{0}$ is known (Anders, 1962).

$A_{0}$ values for each class can be obtained either by averaging observed $\mathrm{Al}^{26}$ contents in meteorites of long radiation age, or by using the empirical $\mathrm{Al}^{26}$ production rates of Fuse and Anders (1969). These $A_{0}$ values represent averages over various meteorite sizes and sample depths, and may thus be inappropriate for samples from very small or very large meteorites. However, the distribution of measured values for chondrites (Figure 3 of Fuse and Anders, 1969) shows that $85 \%$ of all meteorites fall within $\pm 15 \%$ of $\mathrm{A}_{\mathrm{O}}$.

The $\mathrm{He}^{3}$ or $\mathrm{Ne}^{21}$ content of these meteorites is likewise proportional to age:

$$
\mathrm{He}^{3}=\mathrm{P}_{3} \mathrm{t} \text { and } \mathrm{Ne}^{21}=\mathrm{P}_{21} \mathrm{t}
$$

where $\mathrm{P}_{3}$ and $\mathrm{P}_{21}$ are the respective production rates, in ccSTP $\mathrm{g}^{-1} \mathrm{Myr}^{-1}$. These production rates depend on the chemical composition of the meteorite. In view of the scarcity of meteorites with low $\mathrm{Al}^{26}$ contents, we shall find it expedient to pool all available data, normalizing all production rates to those in L-chondrites:

$$
\mathrm{P}_{3, \mathrm{~N}}=\mathrm{f}_{3, \mathrm{NL}} \mathrm{P}_{3, \mathrm{~L}}
$$


Here the subscript $N$ refers to meteorites of class $N$, while $f_{3, N L}$ is a factor compensating for differences in chemical composition. It can be calculated from the production rate relations given by Mazor et al. (1970):

$$
\mathrm{f}_{3, \mathrm{NL}}=[2.06(\mathrm{O}+\mathrm{C})+100]_{\mathrm{N}} /[2.06(\mathrm{O}+\mathrm{C})+100]_{\mathrm{L}}
$$

and $\quad f_{21, \mathrm{NL}}=[2.2 \mathrm{Mg}+1.35 \mathrm{Al}+\mathrm{Si}+0.29 \mathrm{~S}+0.17 \mathrm{Ca}+0.017(\mathrm{Fe}+\mathrm{Ni})]_{\mathrm{N}^{\prime}}$

$$
/[2.2 \mathrm{Mg}+1.35 \mathrm{Al}+\mathrm{Si}+0.29 \mathrm{~S}+0.17 \mathrm{Ca}+0.017(\mathrm{Fe}+\mathrm{Ni})]_{\mathrm{L}}
$$

Chemical symbols represent weight percentages of the corresponding elements in the meteorite. The use of production rate relations introduces some circularity into our argument, but this circularity is definitely second-order. Since nearly all meteorites to be considered are chondrites of essentially similar composition, the chemical factors are close to unity. Errors in the production rate relations thus will tend to cancel.

The primary criteria were $\mathrm{Al}^{26}$ content less than $85 \%$ of saturation value (i.e. radiation age $=2.03$ Myr and noblegas contents corresponding to a radiation age less than 3 Myr). Several meteorites (Pantar, Isoulane, Shytal, and New Concord) met the latter criterion, but not the former, as shown by $\mathrm{Al}^{26}$ measurements of Fuse and Anders (1969), and Herman and Anders (unpublished work). We also eliminated obvious cases of diffusion losses of $\mathrm{He}^{3}$ as shown by $\mathrm{He}_{\mathrm{c}}^{3} / \mathrm{Ne}_{\mathrm{c}}^{21}<3$ (all carbonaceous chondrites; Cullison and Menow), one discordant case in which the $\mathrm{Ne}^{21}$ age was much shorter than the $\mathrm{Al}^{26}$ age (Menow), and two cases of a two-stage irradiation (Ivuna, 
Serra de Magé; Fuse and Anders, 1969).

The data are shown in Figures 1 and 2. On the whole, they fit a linear trend, the largest exceptions being Malotas, and especially Appley Bridge. The $\mathrm{Al}^{26}$ measurements on both meteorites were done with great care, and it would therefore be desirable to re-check the noble gas data. For the time being, we have fitted two regression lines to the data; one with and one without Appley Bridge. The data are given in Table 2 .

\section{SCUSSION}

The production rates found fall between the conventional ones of Kirsten et al. (1963) and the revised ones of Kruger and Heymann (1968). We have somewhat more faith in the rates calculated without Appley Bridge. They exceed the conventional $\mathrm{He}^{3}$ and $\mathrm{Ne}^{21}$ rates by the same amount: $24=9 \%$ and $24 \pm 7 \%$.

The error limits of our production rates probably are realistic estimates of their accuracy. The half-life of $\mathrm{Al}^{26}$ (0.738 \pm 0.029 Myr, Rightmire and Kohman, 1958) contributes an error of only $4 \%$. The $\mathrm{A}_{\mathrm{O}}$ estimate is somewhat more uncertain, owing to variations in the effective cosmic-ray flux. But such variations affect $\mathrm{Al}^{26}$ and $\mathrm{He}^{3}, \mathrm{Ne}^{21}$ to about the same degree. Hence the exrors tend to offset each other, especially in the region where the growth curve is approximately linear. Elsewhere they will contribute to the overall scatter, which is taken into account in the regression.

$$
\text { Allowing for the uncertainty in the } A 1^{26} \text { half-life, we }
$$


obtain the following error estimates:

$$
\begin{array}{lll}
\mathrm{He}^{3} & 2.48 \pm 0.23 & \mathrm{ccsTP} \mathrm{g}^{-1} \mathrm{Myr}^{-1} \\
\mathrm{Ne}^{21} & 0.466 \pm 0.031 & \mathrm{ccsTP} \mathrm{g}^{-1} \mathrm{Myr}^{-1}
\end{array}
$$

Judging from these production rates, it would seem that all published radiation ages of stony meteorites based on conventional rates will have to be shortened by a factor of 0.81 . Future work may permit still more accurate determination of absolute production rates.

Acknowledgments. We are indebted to G.F. Herman and R. Ganapathy for permission to quote unpublished $\mathrm{AI}^{26}$ and noble-gas measurements. This work was supported in part by the U.S. AEC, Contract AT(11-1)-382 and NASA Grant NGL 
Anders E. (1962) Two meteorites of unusually short cosmic-ray exposure age. Science 138, 431-433.

Anders E. (1963) Meteorite ages. In The Moon, Meteorites and Comets, The Solar System, Vol. IV (eds. B.M. Middlehurst and G.P. Kuiper), Chap. 13, pp. 402-495. Univ. of Chicago Press, Chicago.

Bainbridge A.E., Suess H.E., and Wänke H. (1962) The tritium content of three stony meteorites. Geochim. Cosmochim. Acta $26,471-473$.

Begemann F. (1966) Tritium content of two chondrites. Earth and Plan. Sci. Lett. 1, 148-150.

Begemann F., Eberhardt P., Hess D.C. (1959) $\mathrm{He}^{3}-\mathrm{H}^{3}-$ Strahlungsalter eines Steinmeteoriten. Z. Naturforsch. 14a, 500-503.

Fuse K. and Anders E. (1969) Aluminum-26 in meteorites--VI. achondrites. Geochim. Cosmochim. Acta 33, 653-670.

Geiss J., Oeschger H., and Signer P. (1960) Radiation ages of chondrites. Z. Naturforsch. 15a, 1016-1017.

Goebel K. and Schmidlin P. (1960) Tritium-Messungen an Steinmeteoriten. Z. Naturforsch. 15a, 79-82. Heymann D. (1965) Cosmogenic and radiogenic $\mathrm{He}, \mathrm{Ne}$, and $\mathrm{Ar}$ in amphoteric chondrites. J. Geophys. Res. 20, 3735-3743. Heymann D. (1967) On the origin of hypersthene chondrites: ages and shock-effects of black chondrites. Icarus 6 , $189-221$. 
Heymann D. and Anders E。 (1967) Meteorites with short cosmicray exposure ages, as determined from their $\mathrm{Al}^{26}$ content. Geochim. Cosmochim. Acta 31, 1793-1810.

Heymann D., Mazor E., and Anders E. (1968) Ages of calciumrich achondrites--I. Eucrites. Geochim. Cosmochim. Acta 32, $1241-1268$.

Hintenberger H., König H., Schultz L., and Wänke H. (1964) Radiogene, spallogene und primordiale Edelgase in Steinmeteoriten. Z. Naturforsch. 19a, 327-341.

Kirsten T., Krankowsky D., and Zähringer J. (1963) Edelgas- und Kalium-Bestimmungen an einer grösseren Zahl von Steinmeteoriten. Geochim. Cosmochim. Acta 27, 13-42.

Kruger S.T. and Heymann D. (1968) Cosmic-ray-produced hydrogen 3 and helium 3 in stony meteorites. J. Geophys. Res. $23,4784-4787$.

Mazor E., Heymann D., and Anders E. (1970) Noble gases in carbonaceous chondrites. Geochim. Cosmochim. Acta 34, 781-824. Rightmire R.A. and Kohman T.P. (1958) über die Halbwertszeit des langlebigen ${ }^{26} \mathrm{Al}$. Z. Naturforsch. 13a, 847-853. Schaeffer O.A. and Zähringer J. (1958) Helium- und ArgonErzeugung in Eisentargets durch energiereiche Protonen Z. Naturforsch. 13a, 346-347. Zähringer J. (1968) Rare gases in stony meteorites. Geochim. Cosmochim. Acta 32, 209-237. 
TABLE 1 Meteorites with low $\mathrm{Al}^{26}$ Contents

\begin{tabular}{|c|c|c|c|c|c|c|c|c|c|c|}
\hline Meteorite & Class & $\begin{array}{c}\mathrm{Al}^{26} \\
\mathrm{dpm} / \mathrm{kg}\end{array}$ & $\operatorname{Re} f$ & $\underset{\mathrm{dpm} / \mathrm{kg}}{\mathrm{A}_{\mathrm{O}}}$ & $\stackrel{t}{\operatorname{myr}}$ & $\begin{array}{l}\mathrm{He}_{\mathrm{c}}^{3} \\
\mathrm{ccSTP} /\end{array}$ & $\mathrm{Ne}_{\mathrm{c}}^{21}$ & $\operatorname{Ref}$ & $\mathrm{f}_{3, \mathbb{N L}}$ & $\mathbb{f}_{21, N L}$ \\
\hline Cold Bokkeveld & $\mathrm{C} 2$ & $12.9 \pm 0.9$ & 4 & $47.0=4.7$ & $0.34 \pm 0.05$ & 0.23 & 0.09 & 8 & & 0.75 \\
\hline Mighei & $\mathrm{C} 2$ & $35.6 \pm 2.0$ & 7 & $47.6 \pm 4.8$ & $1.48_{-0.31}^{+0.44}$ & 1.66 & 0.66 & 8 & & 0.76 \\
\hline Nogoya & $\mathrm{C} 2$ & $6 \pm 3$ & 4 & $47.1 \pm 4.7$ & $0.15 \pm 0.08$ & 0.16 & 0.055 & 8 & & 0.76 \\
\hline Pollen & $\mathrm{C} 2$ & $31 \pm 6$ & 4 & $48.6 \pm 4.9$ & $1.11_{-0.35}^{+0.53}$ & $\underline{1.14}$ & 0.40 & 8 & & 0.78 \\
\hline Grosnaja & $\mathrm{C} 3$ & $43.3 \pm 1.7$ & 4 & $53.1 \pm 5.3$ & $1.82+0.69$ & 0.88 & 0.70 & 8 & & 0.87 \\
\hline Adhi Kot & E3 & $50.9 \pm 2.1$ & 10 & $60.1 \pm 6.0$ & $2.01_{-0.50}^{+0.96}$ & 4.7 & 0.8 & 6 & 0.93 & 0.79 \\
\hline St, Marks & E5 & $33 \pm 3$ & 4 & $60.1 \pm 6.0$ & $0.86 \pm 0.14$ & 1.3 & 0.3 & 1 & 0.93 & 0.85 \\
\hline Cullison & $\mathrm{H} 4$ & $41.8 \pm 4.8$ & 11 & $60.1 \pm 6.0$ & $1.26_{-0.31}^{+0.44}$ & 0.79 & 0.55 & 2 & 1.00 & 0.93 \\
\hline Malotas & $\mathrm{H}$ & $37.9 \pm 1.4$ & 10 & $60.1 \pm 6.0$ & $1.07_{-0.18}^{+0.21}$ & 3.7 & 0.63 & 2 & 1.00 & 0.93 \\
\hline Timochin & H5 & $17.9 \pm 1.3$ & 10 & $60.1 \pm 6.0$ & $0.38 \pm 0.06$ & 0.94 & 0.17 & 9 & 1.00 & 0.93 \\
\hline Ladder Creek & L6 & $39.7 \pm 2.4$ & 10 & $65.6 \pm 6.6$ & $\begin{array}{r}1.00+0.16 \\
-0.15\end{array}$ & 1.55 & 0.32 & 2 & 1.00 & 1.00 \\
\hline Shaw & L6 & $20 \pm 2$ & 4 & $67.7 \pm 6.8$ & $0.39 \pm 0.06$ & 0.90 & 0.22 & 3 & 1.00 & 1.00 \\
\hline Appley Bridge & LL6 & $48 \pm 2$ & 4 & $65.8 \pm 6.6$ & $1.37_{-0.27}^{+0.36}$ & $\underline{1.76}$ & 0.30 & 3 & 1.00 & 1.00 \\
\hline Shergotty & $\mathrm{Eu}$ & $66.4 \pm 3.1$ & 7 & $81.0 \pm 8.1$ & $1.83_{-0.43}^{+0.71}$ & 4.9 & 0.52 & 5 & 1.10 & 0.79 \\
\hline
\end{tabular}


Kirsten, Krankowsky and Zähringer, 1963

Hintenbeger et al., 1964

Heymann, 1965

Heymann and Anders, 1967

Heymann, Mazor and Anders, 1968

Zähringer, 1968

Fuse and Anders, 1969

Mazor, Heymann and Anders, 1970

Ganapathy, unpubl ished work

Herman and Anders, unpublished work

Herzog, unpublished work 


\section{TABLE 2}

Production Rates of $\mathrm{He}^{3}$ and $\mathrm{Ne}^{21}$ in $L$ Chondrites

Reference

Production Rate, $10^{-8} \operatorname{coSTP~}^{-1} \mathrm{Myr}^{-1}$

$\mathrm{He}^{3} \quad \mathrm{Ne}^{21}$

Kirsten et al. (1963)

2.00

$0.377 *$

Kruger and Heymann (1968)

2.60

$0.491 *$

This work (without Appley

Bridge) ${ }^{\dagger}$

$2.48 \pm 0.20 \quad 0.466 \pm 0.024$

This work (with Appley Bridge) ${ }^{\dagger}$

$2.30 \pm 0.23 \quad 0.440 \pm 0.030$

* Calculated from $\mathrm{He}^{3}$ production rate on the basis of the average $\mathrm{He}^{3} / \mathrm{Ne}^{21}$ ratio in L chondrites, 5.30 .

$\dagger$ The errors quoted, which come directly from the regression analysis, do not include the uncertainty in the half-life of $A 1^{26}$ (see text). 


\section{FIGURE CAPTIONS}

Figure 1. $\mathrm{He}^{3}$ contents of stony meteorites, adjusted to level of L-chondrites (see text). Doubtful values are shown by open symbols. The regression line and its error limits are indicated by solid and dashed lines. Symbols: $A B=$ Appley Bridge, $\mathrm{AK}=$ Adhi Kot, $\mathrm{LC}=$ Ladder Creek, $\mathrm{Ma}=$ Malotas, $\mathrm{SM}=\mathrm{St}$. Marks, $\mathrm{Sh}=$ Shaw, $\mathrm{Sg}=$ Shergotty, $\mathrm{Ti}=$ Timochin.

Figure 2. $\mathrm{Ne}^{21}$ contents of stony meteorites, adjusted to level of L-chondrites (see text). Other notation as in Figure 1 with the following additional symbols: $\mathrm{CB}=$ Cold Bokkeveld, $\mathrm{Cu}=$ Cullison, $\mathrm{Gr}=$ Grosnaja, $\mathrm{Mi}=$ Mighei, No $=$ Nogoya, Po $=$ Pollen. 


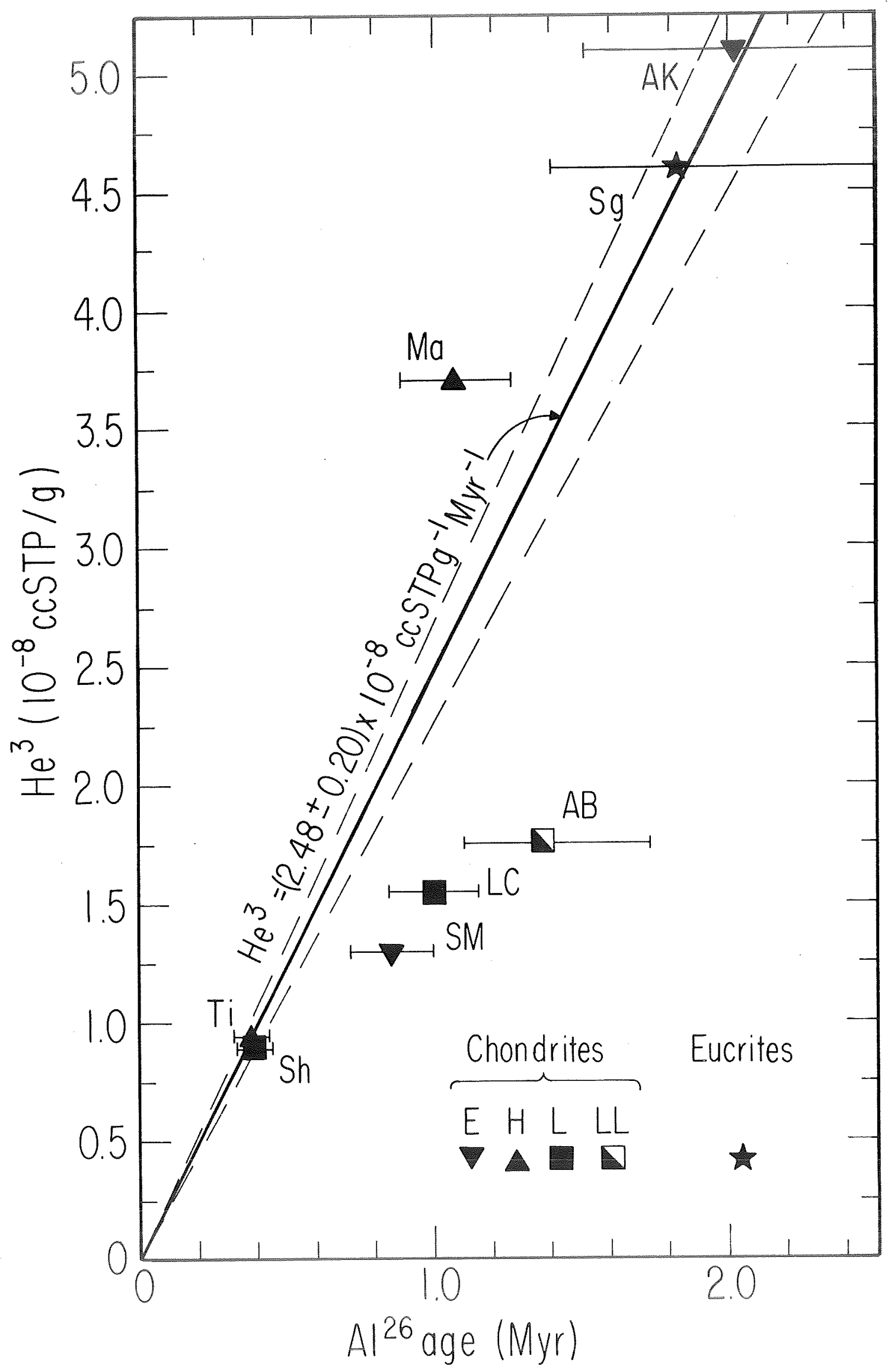

Fig. I 


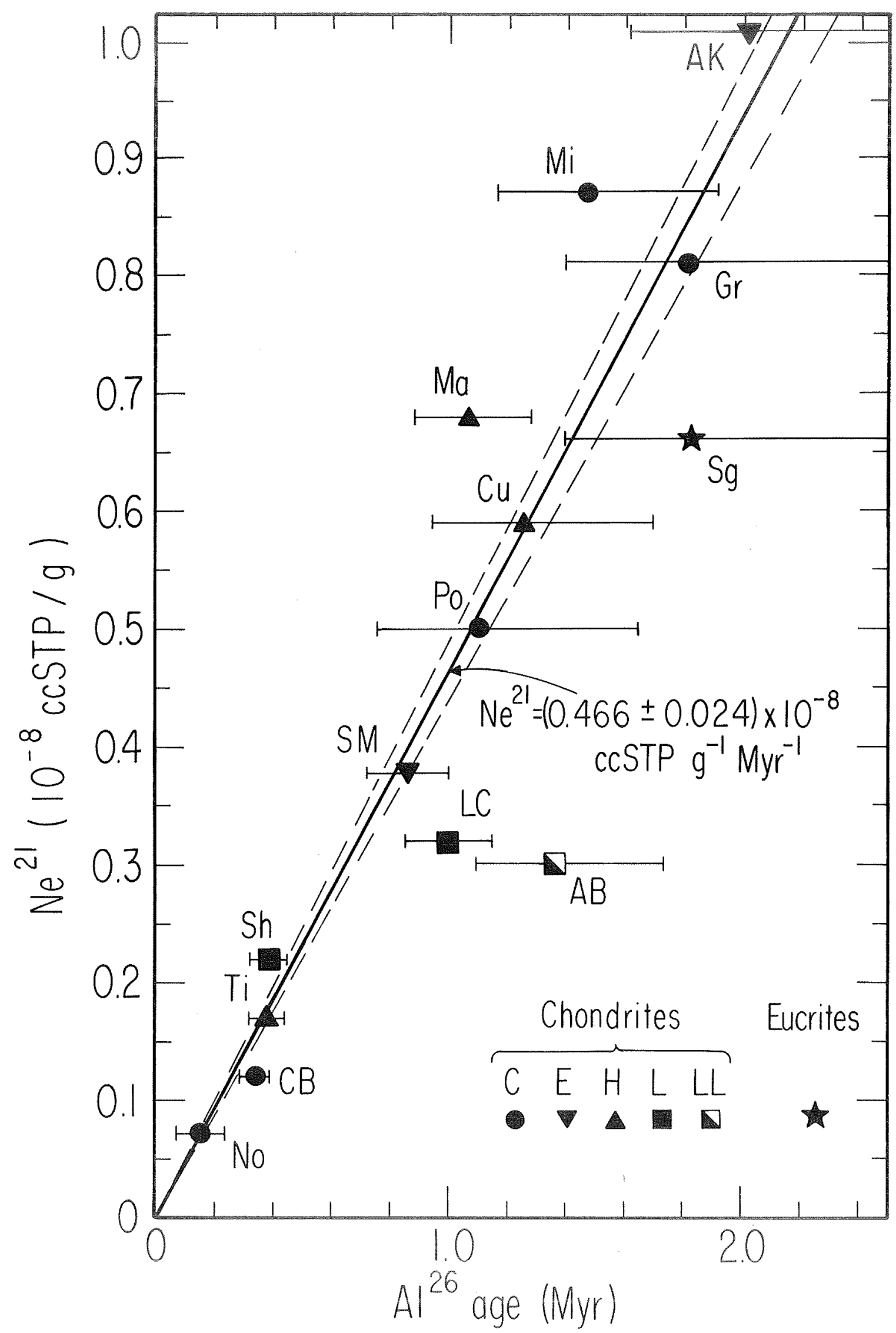

Fig. 2 